\title{
CRESCIMENTO, NUTRIÇÃO MINERAL E NÍVEL CRÍTICO FOLIAR DE K EM MUDAS DE UMBUZEIRO, EM FUNÇÃO DA ADUBAÇÃO POTÁSSICA ${ }^{1}$
}

\author{
Growth, mineral nutrition and foliar critical level of $K$ in umbuzeiro seedlings, \\ in function of the potassium fertilization
}

\author{
Orlando Sílvio Caires Neves ${ }^{2}$, Janice Guedes de Carvalho ${ }^{3}$, Eric Victor de Oliveira Ferreira ${ }^{4}$, Natália Victor Pereira ${ }^{4}$
}

\section{RESUMO}

O umbuzeiro (Spondias tuberosa Arr. Cam.) é uma frutífera originária da região nordeste do Brasil e se caracteriza pela alta tolerância à seca. $\mathrm{O}$ crescimento, a nutrição mineral e o nível crítico foliar de potássio em mudas de umbuzeiros crescidas num Latossolo Vermelho distroférrico, em função de doses de potássio, foram avaliados neste experimento. O delineamento experimental utilizado foi o de blocos casualizados com quatro repetições e seis doses de potássio $\left(0,30,60,120,240\right.$ e $\left.480 \mathrm{mg} \mathrm{dm}^{-3}\right)$. A adubação potássica foi realizada parceladamente, em quatro aplicações, tendo como fontes o sulfato de potássio e o cloreto de potássio. Enquanto para atingir a máxima produção de folhas a dose de potássio foi de $137 \mathrm{mg} \mathrm{dm}^{-3}$, a máxima produção de raízes só aconteceu na dose de $229 \mathrm{mg} \mathrm{dm}^{-3}$. Os teores foliares de potássio nas mudas do umbuzeiro aumentaram com a adubação potássica. O nível crítico de potássio nas folhas das mudas do umbuzeiro variou de 3,40 a $6,04 \mathrm{~g} \mathrm{~kg}^{-1}$.

Termos para indexação: Spondias tuberosa, potássio.

\begin{abstract}
The umbuzeiro (Spondias tuberosa Arr. Cam.) is original of the Northeast of Brazil and it is characterized by tolerance to the drought. The growth, the mineral nutrition and the foliar critical level of potassium in umbuzeiro seedlings, grown in distroferric Red Latosol, in function of potassium doses, were evaluated in this experiment. The experimental design was randomized blocks with four replications and six doses of potassium $\left(0,30,60,120,240\right.$ and $\left.480, \mathrm{mg} \mathrm{dm}^{-3}\right)$. The potassium fertilization was accomplished in four applications, and the used sources were potassium sulfate and the potassium chloride. The highest production of leaves occurred in the dose of $137 \mathrm{mg} \mathrm{dm}^{-3}$ of potassium and the highest production of roots at the dose of $229 \mathrm{mg} \mathrm{dm}^{-3}$ of potassium. The foliar contents of potassium in the umbuzeiro seedlings increased with the potassium fertilization. The critical level of potassium in the leaves of the umbuzeiro seedlings ranged from 3.40 to $6.04 \mathrm{~g} \mathrm{~kg}^{-1}$.
\end{abstract}

Index terms: Spondias tuberosa, potassium.

(Recebido em 15 de julho de 2005 e aprovado em 22 de agosto de 2006)

\section{INTRODUÇÃO}

O umbuzeiro (Spondias tuberosa Arr. Cam.) é uma frutífera adaptada a sobreviver e produzir sob condição de estresse hídrico. Apesar de sua distribuição ser dispersa, consagra-se como uma espécie frutífera de grande importância econômica, social e ecológica para o semiárido nordestino (SILVA et al., 1987). A comercialização dos frutos, colhidos de forma extrativista, representa uma fonte de renda importante para muitas famílias nordestinas, chegando a contribuir com até a metade da renda média anual das mesmas (GONDIM et al., 1991). Assim, pode-se pensar no umbuzeiro como uma alternativa viável para o desenvolvimento agrícola da região semi-árida do Nordeste do Brasil.
Neves (2003), embasado em citações de vários autores, relata a escassez de estudos sobre o umbuzeiro. Até então, apesar da importância que essa planta apresenta para os sertanejos, existem poucos trabalhos publicados, destacadamente na área da nutrição mineral.

A deficiência de $\mathrm{K}$ em umbuzeiros caracteriza-se, inicialmente, por uma clorose das folhas mais novas (rede verde fina das nervuras sobre fundo amarelado); esse sintoma também é descrito para a deficiência de Fe. Malavolta et al. (1997) citam que em algumas culturas a deficiência de K induz a uma deficiência de Fe devido ao acúmulo desse último nos internódios (dificuldades no transporte). Posteriormente, com o agravamento da deficiência é observada uma pequena necrose marginal

${ }^{1}$ Parte da Tese de Doutorado do primeiro autor apresentada à Universidade Federal de Lavras/UFLA.

Engenheiro Agrônomo, Doutor em Solos e Nutrição de Plantas, Professor Adjunto - Universidade Federal Rural de Pernambuco/UFRPE - Rua Ernesto Dourado, 82, Heliópolis - 55296-190 - Garanhuns, PE - silvio@ufrpe.br

${ }^{3}$ Engenheira Agrônoma, Professora Titular - Departamento de Ciência do Solo/DCS - Universidade Federal de Lavras/UFLA - Cx. P. 3037 - $37200-000$ Lavras, MG - janicegc@ufla.br - Bolsista CNPq.

${ }^{4}$ Graduandos em Agronomia - Universidade Federal de Lavras/UFLA - Cx. P. 3037 - 37200-000 - Lavras, MG - ericsolos@yahoo.com.br, nataliavictor@bol.com.br - Bolsistas CNPq. 
das pontas das folhas, iniciando-se pelas folhas mais velhas (CARVALHO et al., 2004; CARVALHO \& NEVES, 2004).

Realizou-se este trabalho com o objetivo avaliar o crescimento, a nutrição mineral e o nível crítico foliar de $\mathrm{K}$ em mudas de umbuzeiros cultivadas num Latossolo Vermelho distroférrico, em função da adubação potássica.

\section{MATERIAL E MÉTODOS}

O experimento foi realizado em casa-de-vegetação do Departamento de Ciência do Solo da Universidade Federal de Lavras (Lavras-MG), definida geograficamente pelas coordenadas de $21^{\circ} 14^{\prime}$ de latitude sul e $45^{\circ} 00$ ' de longitude oeste, com altitude de $910 \mathrm{~m}$, sendo conduzido de julho de 2004 a fevereiro de 2005.

O delineamento experimental utilizado foi o de blocos casualizados com quatro repetições e seis doses de $\mathrm{K}\left(0,30,60,120,240\right.$ e $\left.480 \mathrm{mg} \mathrm{dm}^{-3}\right)$. A parcela foi composta por vasos com capacidade para $8 \mathrm{dm}^{3}$, com altura de $50 \mathrm{~cm}$, preenchidos com Latossolo Vermelho distroférrico, cuja caracterização química se encontra na Tabela 1, com uma planta por vaso. A adubação potássica foi realizada parceladamente, em quatro aplicações, via solução, tendo como fontes o sulfato de potássio e o cloreto de potássio.

A calagem foi feita com $\mathrm{CaCO}_{3}$ e $\mathrm{MgCO}_{3}$ (p.a.), na relação 3:1 (Ca:Mg), visando a elevação do nível de saturação por bases a 80\% (NEVES et al., 2004). Depois de peneirado, o solo foi misturado aos corretivos e incubado por quinze dias. A adubação complementar, em $\mathrm{mg} \mathrm{dm}^{-3}$, incluindo o $\mathrm{S}$ aplicado quando da adubação potássica, foi a seguinte: $\mathrm{N}=300 ; \mathrm{P}=200 ; \mathrm{S}=60 ; \mathrm{B}=0,5 ; \mathrm{Cu}=1,5 ; \mathrm{Zn}=$ 5,0 e $\mathrm{Mo}=0,1$.

A reposição de umidade foi feita diariamente, utilizando-se água deionizada para elevar a $60 \%$ do volume total de poros, sendo o volume a ser adicionado determinado através de pesagens dos vasos.

As sementes passaram pelo processo de quebra de dormência através de escarificação mecânica, conforme recomendação de Nascimento et al. (2000), e foram germinadas em vermiculita. Após 20 dias da emergência, as mudas com altura média de $9,5 \mathrm{~cm}$ foram transplantadas para vasos com os tratamentos.

Ao final do experimento foram avaliados a altura $(\mathrm{cm})$ e o diâmetro do caule $(\mathrm{mm})$ na altura do colo e, depois de colhido, o material vegetal foi separado em raízes, caule e folhas, lavado em água corrente e destilada, seco em estufa a $70^{\circ} \mathrm{C}$ até peso constante e a matéria seca correspondente a cada uma das partes foi pesada ( $\mathrm{g}$ planta ${ }^{-}$ ${ }^{1}$ ) e moída; em seguida, foram realizadas as determinações químicas para os teores dos nutrientes no caule e nas folhas (MALAVOLTA et al., 1997). Ainda, calculou-se a relação parte aérea / raiz.

Através do extrato nítrico-perclórico foram determinados os teores de $\mathrm{P}$ por colorimetria; $\mathrm{Ca}, \mathrm{Mg}, \mathrm{Cu}$, $\mathrm{Fe}, \mathrm{Mn}$ e Zn por espectrofotometria de absorção atômica; $\mathrm{K}$ e Na por fotometria de chama; $\mathrm{S}$ por turbidimetria do sulfato de bário; $\mathrm{N}$ total pelo método semimicro Kjeldahl; e os teores de B, após digestão por via seca, foram determinados por colorimetria (método da curcumina) (MALAVOLTA et al., 1997).

A partir dos teores dos nutrientes e com base na matéria seca das plantas, calculou-se o acúmulo dos elementos na parte aérea das mudas de umbuzeiro (somatório do acúmulo no caule e nas folhas).

Os dados obtidos foram submetidos à análise variância mediante significância do teste $\mathrm{F}$ e, quando significativos, realizaram-se análises de regressão. As análises de variância e de regressão foram feitas com o auxílio do programa estatístico SISVAR (FERREIRA, 2000).

$\mathrm{O}$ nível crítico foliar de $\mathrm{K}$ foi obtido estimando-se a dose de $\mathrm{K}$ aplicada ao solo que proporcionou a produção de $90 \%$ da matéria seca das mudas de umbuzeiro e aquela acima do ponto de máxima eficiência física que proporcionou uma redução de $10 \%$ na produção. Em seguida, essas doses foram substituídas na equação de regressão para os teores foliares $\mathrm{K}$, obtendo-se, assim, uma faixa correspondente ao nível crítico desse nutriente.

TABELA 1 - Análise química do solo (Latossolo Vermelho distroférrico) utilizado no experimento*.

\begin{tabular}{|c|c|c|c|c|c|c|c|c|c|c|c|c|c|c|}
\hline pH & $\mathbf{P}$ & $\mathbf{K}$ & $\mathrm{Ca}$ & Mg & Al & $\mathbf{H}+\mathbf{A l}$ & MO & $\mathbf{Z n}$ & $\mathrm{Fe}$ & Mn & $\mathbf{C u}$ & B & $\mathrm{S}-S O_{4}^{-}$ & $\mathbf{V}$ \\
\hline $\mathrm{H}_{2} \mathrm{O}$ & $\mathrm{mg}$ & $m^{-3}$ & & $\mathrm{~cm}$ & $\mathrm{l}_{\mathrm{c}} \mathrm{dm}$ & & dag $\mathrm{kg}^{-}$ & \multicolumn{6}{|c|}{$\mathrm{mg} \mathrm{dm}^{-3}$} & $\%$ \\
\hline 4,9 & 1,2 & 13 & 0,7 & 0,2 & 0,9 & 7,0 & 3,0 & 1,2 & 47,3 & 4,8 & 1,5 & 0,4 & 8,9 & 13,3 \\
\hline
\end{tabular}

* pH em água; $\mathrm{P}, \mathrm{K}, \mathrm{Fe}, \mathrm{Zn}, \mathrm{Mn}$ e Cu pelo extrator Mehlich-1; Ca, Mg e Al pelo extrator $\mathrm{KCl} 1 \mathrm{~N}$; B - extrator água quente; $\mathrm{H}+\mathrm{Al}$ pelo extrator $\mathrm{SMP}$ e; $\mathrm{S}_{-} \mathrm{SO}_{4}^{-}$pelo extrator fosfato monocálcico em ácido acético. 


\section{RESULTADOS E DISCUSSÃO}

\section{Crescimento}

A adubação potássica influenciou significativamente a altura, o diâmetro do caule, o acúmulo de matéria seca de raiz, caule, folha e total e a relação parte aérea / raiz das mudas do umbuzeiro. Esse resultado indica que o $\mathrm{K}$ existente naturalmente no solo não foi suficiente para sustentar o adequado crescimento dos umbuzeiros e que a adição do mesmo estimulou o desenvolvimento das plantas.

Na Figura 1, estão apresentados os resultados da altura das plantas, diâmetro do caule, matéria seca de raiz, caule, folhas e total e da relação parte aérea / raiz. Observase que com o aumento das doses de $\mathrm{K}$ até o nível de 187 $\mathrm{mg} \mathrm{dm}{ }^{-3}$, as mudas de umbuzeiro responderam em altura; em doses superiores a esta, as plantas apresentaram menor crescimento, relacionado, possivelmente, ao o excesso de $\mathrm{K}$ aplicado nas doses mais altas. Já para o diâmetro do caule das mudas do umbuzeiro, o $\mathrm{K}$ aplicado ao solo apresentou efeito negativo, ou seja, com o aumento das doses houve uma redução linear dessa medida.

Para a matéria seca das folhas (Figura $1 \mathrm{c}$ ), na dose calculada de $137 \mathrm{mg} \mathrm{dm}^{-3}$ de $\mathrm{K}$, o umbuzeiro atingiu sua máxima produção física $\left(1,99 \mathrm{~g} \mathrm{planta}^{-1}\right)$. Provavelmente, nas doses mais altas o potássio foi absorvido e, devido à sua alta mobilidade na planta, foi translocado para as folhas, apresentando-se como tóxico às mesmas.

A espessura do caule decresceu linearmente com a adubação potássica; já a altura das mudas teve comportamento quadrático e, como resultado da ponderação dessas duas variáveis, a matéria seca do caule (Figura $1 \mathrm{c}$ ) foi aumentada até a dose estimada de $192 \mathrm{mg}$ $\mathrm{dm}^{-3}$ de K, quando atingiu 2,60 g planta ${ }^{-1}$, sendo reduzida a partir dessa dose. Já as raízes (Figura 1 d) apresentaram aumento na produção de matéria seca até a dose de $229 \mathrm{mg} \mathrm{dm}^{-3}$ de K, com acentuada redução a partir dessa dose. Por ser uma planta adaptada a condições de estresse hídrico e o mecanismo dessa adaptação estar localizado nas raízes, essa parte do umbuzeiro foi menos prejudicada nas maiores doses de $\mathrm{K}$.

A matéria seca total das mudas do umbuzeiro, devido ao aumento na produção das raízes, apresentou incremento até a dose de $208 \mathrm{mg} \mathrm{dm}^{-3} \mathrm{de} \mathrm{K}$; nessa dose, a produção foi de 11,64 $\mathrm{g} \mathrm{planta}^{-1}$ (Figura $1 \mathrm{~d}$ ).

Ao se comparar a relação percentual entre as três partes estudadas (matéria seca de raiz, caule e folhas), na dose de máxima produção de matéria seca total (208 mg $\mathrm{dm}^{-3}$ de K), verifica-se que $61,0 \%$ da matéria seca das mudas do umbuzeiro foram alocadas no sistema radicular,
$22,3 \%$ no caule e $16,7 \%$ nas folhas. É importante observar que mesmo bem nutrido em $\mathrm{K}$, o umbuzeiro concentrou a maior parte dos compostos orgânicos fotoassimilados no sistema radicular.

A relação parte aérea / raiz (Figura 1 e) apresentou uma redução com o aumento das doses de $\mathrm{K}$ aplicadas ao solo, sendo esse efeito devido a uma maior adaptação das raízes em conviverem com concentrações salinas mais elevadas, conforme sugerido por Neves (2003). A produção de matéria seca das raízes, mesmo nas doses que proporcionaram redução de produção, foi menos prejudicada que a produção de matéria seca do caule e das folhas. Comparativamente, da dose $0 \mathrm{mg} \mathrm{dm}^{-3}$ de $\mathrm{K}$ para a dose de $480 \mathrm{mg} \mathrm{dm}^{-3}$ de $\mathrm{K}$, a relação parte aérea / raiz foi reduzida em $50 \%$, passando de 0,8 para 0,4 , respectivamente.

\section{Teores e acúmulo de macro e micronutrientes na parte aérea}

As doses de $\mathrm{K}$ aplicadas ao solo influenciaram os teores foliares de $\mathrm{K}$ e $\mathrm{Mg}$ e os teores de $\mathrm{S}$ no caule. Os demais macronutrientes não sofreram influência nos seus teores (caule ou folha) nas mudas de umbuzeiro.

Nas folhas, foram detectados os teores médios de $24,68 \mathrm{~g} \mathrm{~kg}^{-1}$ de N; $1,80 \mathrm{~g} \mathrm{~kg}^{-1}$ de P; $34,51 \mathrm{~g} \mathrm{~kg}^{-1}$ de Ca e 2,28 $\mathrm{g} \mathrm{kg}^{-1} \mathrm{de} \mathrm{S}$, já os teores médios no caule foram: $9,84 \mathrm{~g} \mathrm{~kg}^{-1}$ de N; 0,89 $\mathrm{g} \mathrm{kg}^{-1}$ de P; 4,88 $\mathrm{g} \mathrm{kg}^{-1}$ de K; 6,77 $\mathrm{g} \mathrm{kg}^{-1} \mathrm{de} \mathrm{Ca} \mathrm{e}$ $1,17 \mathrm{~g} \mathrm{~kg}^{-1} \mathrm{de} \mathrm{Mg}$.

É importante destacar que os teores de $\mathrm{K}$ no caule não foram influenciados pelas doses desse nutriente aplicadas ao solo, provavelmente devido ao fato de esse elemento ser altamente móvel nas plantas (MALAVOLTA et al., 1997) e não fazer parte de compostos orgânicos, estando livre nas mesmas (MARSCHNER, 1995). Sabe-se que o $\mathrm{K}$ atua em processos osmóticos, na síntese de proteínas e na manutenção de sua estabilidade, na abertura e fechamento dos estômatos, na permeabilidade da membrana e no controle do pH (MALAVOLTA et al., 1997).

Com o aumento das doses de $\mathrm{K}$, a disponibilidade deste no solo foi aumentada e as mudas do umbuzeiro o absorveram em maior quantidade; conseqüentemente, o seu transporte para as folhas foi aumentado. Como reflexo, o teor foliar de $\mathrm{K}$ incrementou linearmente (Figura $2 \mathrm{a}$ ). $\mathrm{Na}$ dose de $0 \mathrm{mg} \mathrm{dm}^{-3} \mathrm{de} \mathrm{K}$, o teor de $\mathrm{K}$ nas folhas das mudas do umbuzeiro foi de 2,52 $\mathrm{g} \mathrm{kg}^{-1}$, passando para $4,72 \mathrm{~g} \mathrm{~kg}^{-1}$ na dose que proporcionou a maior produção de matéria seca (208 $\left.\mathrm{mg} \mathrm{dm}^{-3} \mathrm{de} \mathrm{K}\right)$, refletindo num aumento de 1,9 vezes, ou de $87 \%$. 
$\mathrm{y}=39,372+0,08873 \mathrm{x}-0,000236 \mathrm{x}^{2} \quad \mathrm{R}^{2}=0,54 * *$

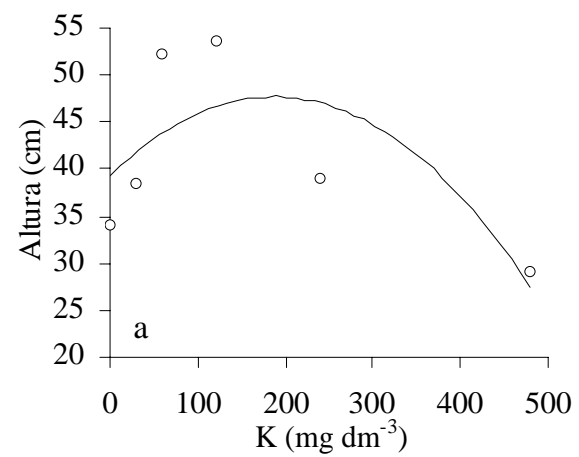

$\operatorname{MSC}\left(\right.$ ) $\mathrm{y}=1,859+0,007696 \mathrm{x}-0,00002 \mathrm{x}^{2} \quad \mathrm{R}^{2}=0,50 *$ $\operatorname{MSF}(-) \mathrm{y}=1,783+0,00302 \mathrm{x}-0,000011 \mathrm{x}^{2} \quad \mathrm{R}^{2}=0,50 * *$

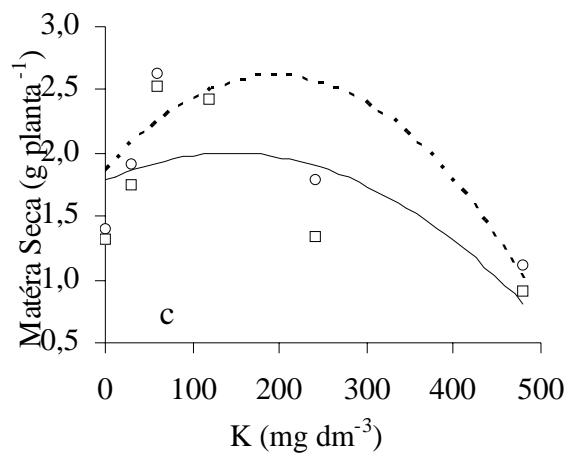

$\mathrm{y}=6,0636-0,0044 \mathrm{x} \quad \mathrm{R}^{2}=0,91 * *$

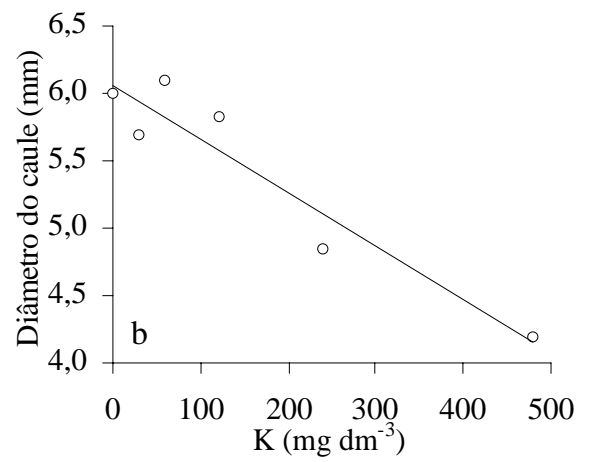

$\operatorname{MSR}(-) \mathrm{y}=4,778+0,020138 \mathrm{x}-0,000044 \mathrm{x}^{2} \quad \mathrm{R}^{2}=0,53 * *$ $\operatorname{MST}(-) \mathrm{y}=8,421+0,030855 \mathrm{x}-0,000074 \mathrm{x}^{2} \quad \mathrm{R}^{2}=0,51 * *$

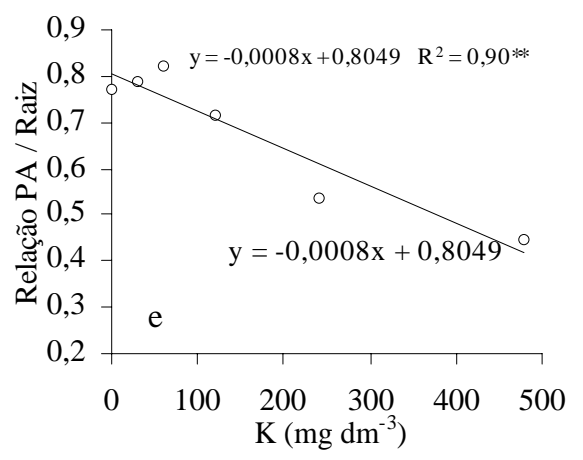

FIGURA 1 - Altura (a), diâmetro do caule (b), matéria seca do caule-MSC e matéria seca das folhas-MSF (c), matéria seca das raízes-MSR e matéria seca total-MST (d) e relação parte aérea / raiz (e) de mudas de umbuzeiro, em função de doses de potássio.

Até a dose estimada de $339 \mathrm{mg} \mathrm{dm}^{-3}$ de $\mathrm{K}$, os teores de $\mathrm{Mg}$ nas folhas das mudas do umbuzeiro sofreram reduções significativas (Figura 2 b). Já os teores de $\mathrm{S}$ no caule foram aumentados de forma linear no sentido do aumento das doses

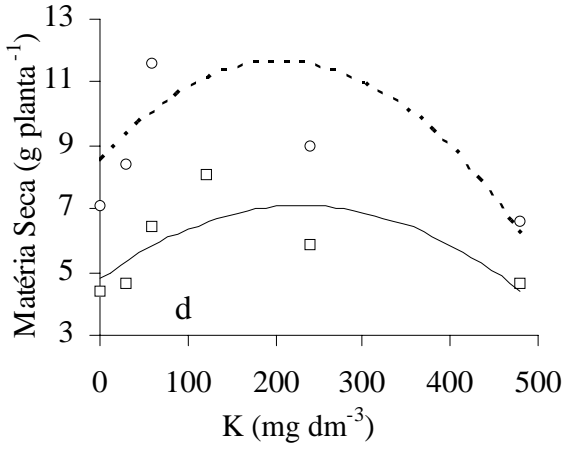




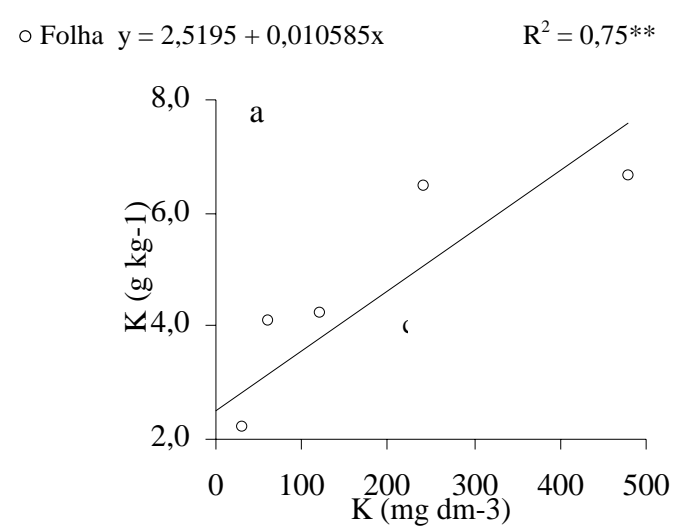

$\square$ Caule $y=0,3216-0,000715 x \quad R^{2}=0,70 * *$

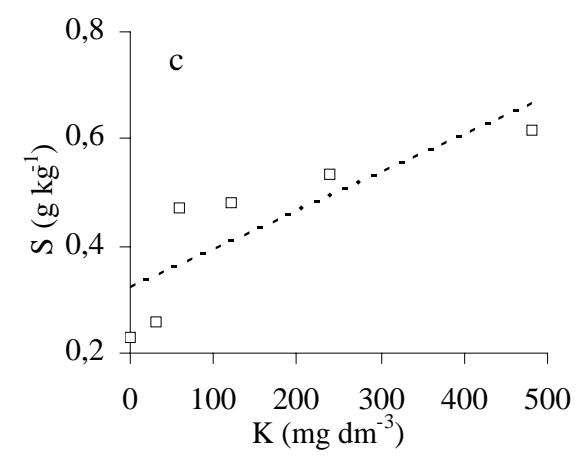

○ Folha $y=4,067-0,012204 x+0,000018 x^{2} \quad R^{2}=0,69 *$
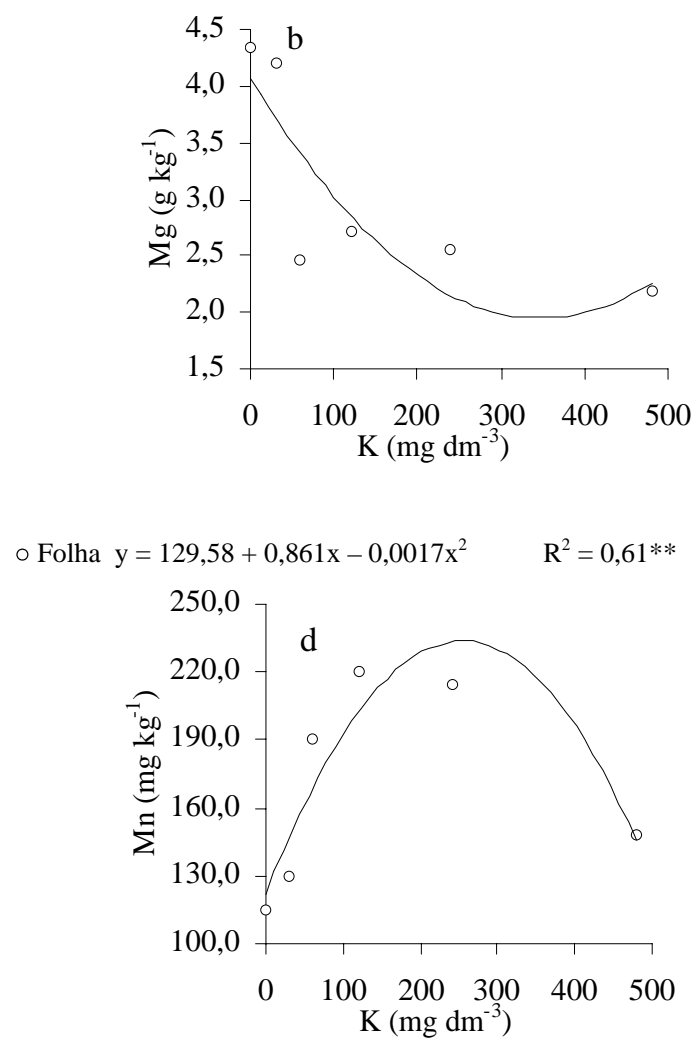

FIGURA 2 - Teores de potássio (a), magnésio (b), enxofre (c) e manganês (d) em mudas de umbuzeiros, em função de doses de $\mathrm{K}$.

Excetuando os teores foliares de Mn, os teores dos demais micronutrientes (folhas e caule) não foram influenciados pela adubação potássica, visto que não houve diferença significativa entre os tratamentos. Nas folhas, os teores médios dos micronutrientes, exceto os de $\mathrm{Mn}$, foram de 42,29 $\mathrm{mg} \mathrm{kg}^{-1}$ de B; 6,41 $\mathrm{mg} \mathrm{kg}^{-1} \mathrm{de} \mathrm{Cu} ; 200,81$ $\mathrm{mg} \mathrm{kg}^{-1}$ de Fe e $13,38 \mathrm{mg} \mathrm{kg}^{-1}$ de $\mathrm{Zn}$. No caule, os teores médios foram: $16,04 \mathrm{mg} \mathrm{kg}^{-1} \mathrm{de} \mathrm{B} ; 3,55 \mathrm{mg} \mathrm{kg}^{-1} \mathrm{de} \mathrm{Cu} ; 14,91$ $\mathrm{mg} \mathrm{kg}{ }^{-1}$ de Fe; 39,33 mg kg-1 de Mn e 5,68 mg kg-1 de Zn.

Segundo Carvalho \& Neves (2004), plantas de umbuzeiro que não são supridas adequadamente com K acumulam Fe no caule, induzindo a deficiência desse último. Apesar de não ser detectada diferença significativa entre os tratamentos, verificou-se que no tratamento que não recebeu adubação potássica os teores de $\mathrm{Fe}$ no caule foram de $18,24 \mathrm{~g} \mathrm{~kg}^{-1} \mathrm{e}$ a média geral foi de $14,91 \mathrm{~g} \mathrm{~kg}^{-1}$.

Dentre todos os nutrientes estudados, apenas os acúmulos de $\mathrm{N}, \mathrm{P}$ e $\mathrm{K}$ na parte aérea das mudas do umbuzeiro foram influenciados pelas doses de $\mathrm{K}$ aplicadas ao solo.

O P acumulado na parte aérea das mudas de umbuzeiro seguiu uma função quadrática, como apresentado na Figura 3a, através da qual se pode observar que na dose calculada de $187 \mathrm{mg} \mathrm{dm}^{-3} \mathrm{de} \mathrm{K}$ foi atingido o máximo acúmulo $\left(0,0061 \mathrm{~g}\right.$ planta $\left.^{-1}\right)$. O mesmo comportamento foi observado para o acúmulo de $\mathrm{N}$ (Figura $3 b$ ), em que a dose calculada de $150 \mathrm{mg} \mathrm{dm}^{-3} \mathrm{de} \mathrm{K}$ proporcionou o acúmulo de $0,072 \mathrm{~g} \mathrm{planta}^{-1}$.

Como reflexo da produção de matéria seca e dos teores de $\mathrm{K}$ nas folhas, o acúmulo de $\mathrm{K}$ na parte aérea das mudas de umbuzeiro foi influenciado pela adubação potássica. O comportamento de resposta para essa variável foi quadrático, com incremento no acúmulo até a dose estimada de $216 \mathrm{mg} \mathrm{dm}^{-3}$ de $\mathrm{K}$, conforme apresentado na Figura 3b. A máxima acumulação atingida na referida dose foi de $0,025 \mathrm{mg}_{\text {planta }}{ }^{-1}$. 


$$
\mathrm{y}=0,0047+0,000015 \mathrm{x}-0,00000004 \mathrm{x}^{2} \quad \mathrm{R}^{2}=0,52 *
$$

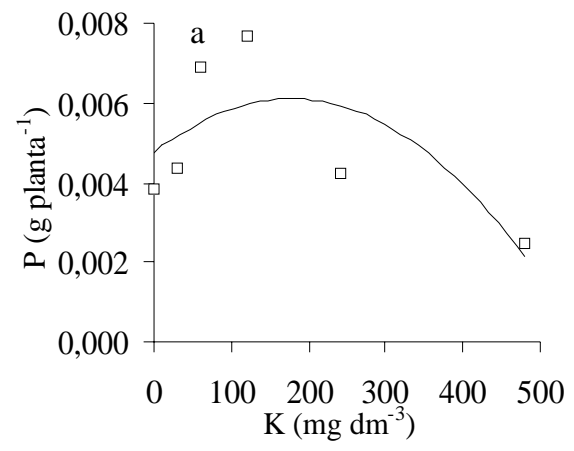

$\mathrm{K}(-) \mathrm{y}=0,0107+0,00013 \mathrm{x}-0,0000003 \mathrm{x}^{2} \quad \mathrm{R}^{2}=0,50 * *$ $\mathrm{N}(-) \mathrm{y}=0,0608+0,00015 \mathrm{x}-0,0000005 \mathrm{x}^{2} \quad \mathrm{R}^{2}=0,53 * *$

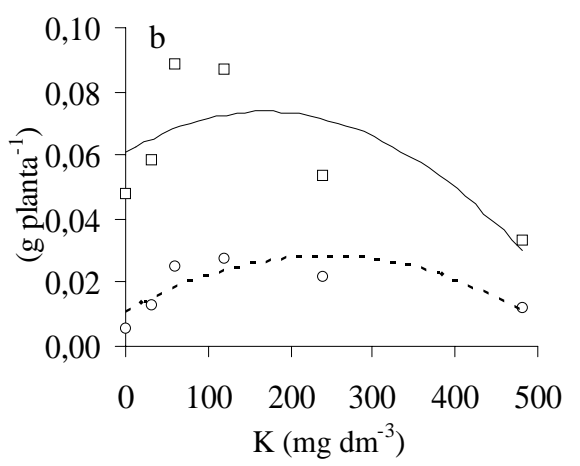

FIGURA 3 - Acúmulo de fósforo (a), de nitrogênio e potássio (b) na parte aérea de mudas de umbuzeiro, em função de doses de $\mathrm{K}$.

\section{Nível crítico foliar de $\mathbf{K}$}

Para atingir a produção máxima de uma cultura são necessárias aplicações de doses de fertilizantes que, às vezes, não são econômicas. Freqüentemente, consideramse doses que proporcionam de $80 \%$ a $90 \%$ do rendimento máximo, as quais se aproximam do rendimento máximo econômico (FAQUIN et al., 1995). Dessa forma, no cálculo do nível crítico de $\mathrm{K}$ foliar nas mudas do umbuzeiro, considerou-se como a produção econômica $90 \%$ da produção máxima. No outro extremo, considerou-se a dose que, após atingida a máxima produção física, reduziu-a em $10 \%$.

Como definido por Fritz (1976), citado por Santos (1999), o nível crítico ou concentração crítica de um nutriente na planta ou no solo pode ser considerado como a concentração abaixo da qual existe probabilidade de resposta da planta à sua adição no solo. Na realidade, o nível crítico refere-se a uma faixa e não a um ponto, e nessa faixa, encontram-se os teores desejáveis dos nutrientes para se obter a máxima produção econômica.

O nível crítico foliar de $\mathrm{K}$ nas mudas de umbuzeiro foi de 3,40 a 6,04 $\mathrm{g} \mathrm{kg}^{-1}$ (Figura 4). Dessa forma, considera-se que mudas de umbuzeiro que apresentarem teores foliares de $\mathrm{K}$ dentro desta faixa estão bem nutridas nesse nutriente. Teores abaixo de $3,40 \mathrm{~g} \mathrm{~kg}^{-1}$ podem indicar deficiência de $\mathrm{K}$ e acima de $6,04 \mathrm{~g} \mathrm{~kg}^{-1}$, excesso.

A determinação do requerimento nutricional e da diagnose nutricional das plantas é baseada na expectativa de que haja estreita correlação entre a disponibilidade do nutriente no solo, o teor do elemento na folha e a produção (MALAVOLTA et al., 1997). Os valores de níveis críticos na parte aérea das plantas, mais propriamente nas folhas, são amplamente utilizados como padrões na interpretação dos resultados de análises foliares, cabendo destacar apenas que a fase de crescimento da cultura tem grande influência sobre os teores dos nutrientes e, para o umbuzeiro, o nível crítico foliar de $\mathrm{K}$ foi determinado para a fase de muda, sendo necessários mais estudos para a determinação do mesmo em outras fases de crescimento. Por exemplo, num experimento de levantamento do estado nutricional de umbuzeiros adultos, em campo e na fase de produção, Silva et al. (1984) encontraram teores foliares de K da ordem de $10 \mathrm{~g} \mathrm{~kg}^{-1}$.

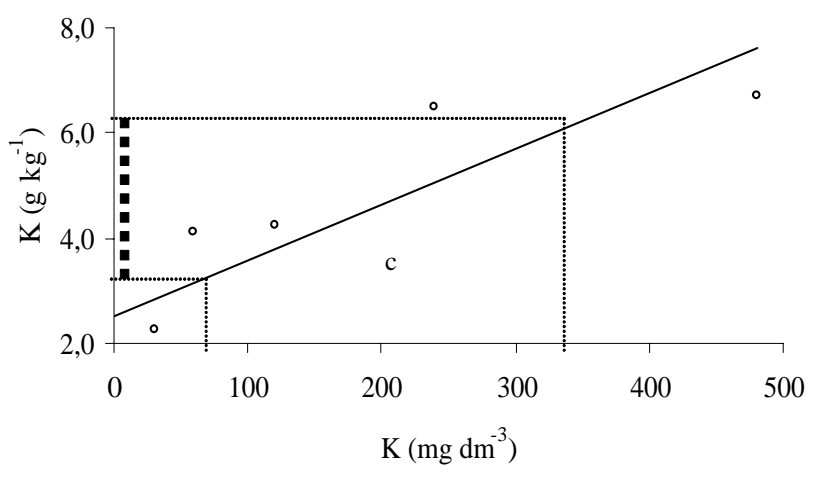

FIGURA 4 - Nível crítico foliar de K em mudas de umbuzeiro. 


\section{CONCLUSÕES}

A máxima produção de matéria seca de folhas pelas mudas de umbuzeiro crescidas em Latossolo Vermelho distroférrico foi atingida na dose estimada de $137 \mathrm{mg} \mathrm{dm}^{-3}$ de K, e a máxima produção de raízes na dose de $229 \mathrm{mg} \mathrm{dm}^{-}$ ${ }^{3}$ de K.

As doses mais altas de $\mathrm{K}$ aplicadas no solo interferiram negativamente no crescimento das mudas de umbuzeiro.

Os teores foliares de $\mathrm{K}$ nas mudas do umbuzeiro aumentaram com a adubação potássica.

O nível crítico de $\mathrm{K}$ nas folhas das mudas do umbuzeiro variou de 3,40 a 6,04 $\mathrm{g} \mathrm{kg}^{-1}$.

\section{REFERÊNCIAS BIBLIOGRÁFICAS}

CARVALHO, J. G.; GONÇALVES, F. C.; NEVES, O. S. C.; GONÇALVES, S. M.; CLEMENTE, F. M. T. Caracterização de sintomas visuais deficiências de macronutrientes em mudas de umbuzeiro. In: CONGRESSO BRASILEIRO DE FRUTICULTURA, 18., 2004, Florianópolis. Anais... Florianópolis: UFSC, 2004. CD-ROM.

CARVALHO, J. G.; NEVES, O. S. C. Umbuzeiro (Spondias tuberosa Arr. Cam.). Lavras: UFLA, 2004. 60 p.

FAQUIN, V.; HOFFMANN, C. R.; EVANGELISTA, A. R. O potasio e o enxofre no crescimento da brachiária e do colonião em amostras de um Latossolo da região noroeste do Paraná. Revista Brasileira de Ciência do Solo, Campinas, v. 19, n. 1, p. 87-94, jan./abr. 1995.

FERREIRA, D. F. Análises estatísticas por meio do SISVAR (Sistema para Análise de Variância) para Windows 4.0. In: REUNIÃO ANUAL DA REGIÃO BRASILEIRA DA SOCIEDADE INTERNACIONAL DE BIOMETRIA, 45., 2000, São Carlos. Anais... São Carlos: UFSCar, 2000. p. 255-258.

GONDIM, T. M. S.; SILVA, H.; SILVA, A. Q.; CARDOSO, E. A. Período de ocorrência de formação de xilopódios em plantas de umbu (Spondias tuberosa Arr. Cam. ) propagadas sexualmente e assexuadamente. A. Revista Brasileira de Fruticultura, Cruz das Almas, v. 13, n. 2, p. 33-38, out. 1991.
MALAVOLTA, E.; VITTI, G. C.; OLIVEIRA, S. A. Avaliação do estado nutricional das plantas: princípios e aplicações. 2. ed. Piracicaba: Potafos, 1997. 319 p.

MARSCHNER, H. Mineral nutrition of higher plant. 2. ed. San Diego: Academic, 1995. 889 p.

NASCIMENTO, C. E. de S.; SANTOS, C. A. F.; OLIVEIRA, V. R. de. Produção de mudas enxertadas de umbuzeiro (Spondias tuberosa Arruda). Petrolina: Embrapa-CPATSA, 2000. 13 p. (Embrapa Semi-árido. Circular técnica, 48).

NEVES, O. S. C. Nutrição mineral e crescimento de mudas de umbuzeiro (Spondias tuberosa Arr. Cam.), em solução nutritica, em função de níveis de salinidade. 2003. 70 p. Dissertação (Mestrado em Solos e Nutrição de Plantas) Universidade Federal de Lavras, Lavras, 2003.

NEVES, O. S. C.; CARVALHO, J. G.; HOJO, R. H. Nível ótimo de saturação por bases para mudas de umbuzeiro cultivadas em latossolo vermelho distroférrico. In: REUNIÃO BRASILEIRA DE FERTILIDADE DO SOLO E NUTRIÇÃO DE PLANTAS, 26; REUNIÃO BRASILEIRA SOBRE MICORRIZAS, 10; SIMPÓSIO BRASILEIRO DE MICROBIOLOGIA DO SOLO, 8.; REUNIÃO BRASILEIRA FERTBIO, 2004, Lages. Anais... Lages: [s.n.], 2004.

SANTOS, H. Q. Níveis críticos de fósforo no solo e na planta para gramíneas forrageiras tropicais, em diferentes idades. 1999. 80 f. Dissertação (Mestrado em Zootecnia) Universidade Federal de Viçosa, Viçosa, 1999.

SILVA, H.; SILVA, A. Q. da; OLIVEIRA, A. R.; CAVALCANTE, F. B. Algumas informações pomológicas do umbuzeiro da Paraíba: II. características tecnológicas. In: CONGRESSO BRASILEIRO DE FRUTICULTURA, 9., 1987, Campinas, SP. Resumos... Campinas: SBF, 1987. v. 1, p. 691-696.

SILVA, H.; SILVA, A. Q. da; ROQUE, M. L.; MALAVOLTA, E. Composição mineral do umbuzeiro (Spondias tuberosa Arr. Cam.). In: CONGRESSO BRASILEIRO DE FRUTICUlTURA, 7., 1983, Florianópolis. Anais... Florianópolis: SBF/EMPASC, 1984. v. 4, p. 1129-1134. 